\title{
El desarrollo de la política forestal e incidencias en el Delta Inferior del Paraná
}

\section{Beatriz Nussbaumer}

Facultad de Agronomía, Cátedra de Extensión y Sociología Rurales, Universidad de Buenos Aires, CONICET, Argentina nussbaum@agro.uba.ar

\section{Sebastián Fernández}

Facultad de Agronomía, Universidad de Buenos Aires. Instituto Nacional de Tecnología Agropecuaria, EEA Delta del Paraná, Argentina fernandez.sebastian@inta.gob.ar

Cita sugerida: Nussbaumer, B. y Fernández, S. (2018). El desarrollo de la política forestal e incidencias en el Delta Inferior del Paraná. Mundo Agrario, 19(41), e089. https://doi.org/10.24215/15155994e089

Recibido: 9 de Mayo 2017 - Aceptado: 8 de Mayo 2018 - Publicado: 15 de Agosto 2018 http://creativecommons.org/licenses/by-nc-sa/4.0/deed.es_AR 


\title{
El desarrollo de la política forestal e incidencias en el Delta Inferior del Paraná
}

\section{Development of forest policy and its incidence on the low region of the Parana Delta}

\section{Beatriz Nussbaumer}

Facultad de Agronomia, Cátedra de Extensión y Sociología Rurales, Universidad de Buenos Aires, CONICET, Argentina

nussbaum@agro.uba.ar

\section{Sebastián Fernández}

Facultad de Agronomía, Universidad de Buenos Aires. Instituto Nacional de Tecnología

Agropecuaria, EEA Delta del Paraná, Argentina

fernandez.sebastian@inta.gob.ar

\section{RESUMEN:}

El artículo realiza un análisis histórico-contextual de las políticas forestales en la Argentina, que permite la identificación de los supuestos que conforman el referencial de esta política sectorial y que legitiman la intervención del Estado en el ámbito privado de la foresto-industria. A través del análisis empírico de los efectos de la aplicación de estas políticas de fomento técnico y financiero en el sector productivo, se propone comprender en qué medida estos instrumentos de política sectorial han favorecido la reconfiguración socio-productiva del Delta Inferior del Paraná hacia la forestalización, con la consecuente emergencia de nuevos perfiles territoriales como el de la Zona Núcleo Forestal

Palabras Clave: Políticas públicas, Referencial sectorial, Forestación, Zona Núcleo Forestal, Paraná.

\begin{abstract}
:
The article develops a historical-contextual analysis of forestry policies in Argentina. This allows the authors the identification of hypotheses that compose the framework (référentiel in French) of the sectorial policy that legitimize state intervention in the private sphere of forestry-industry. Through an empirical analysis about the effects of technical and financial promotion policies applied to the productive sector, it is pursued to understand the modes these sectorial instruments have favored the socioproductive reconfiguration of the Lower Paraná Delta towards forestry expansion. Moreover, it is analyzed how these policies interceded on the emergence of new territorial profiles and agents such as that of the Forest Nucleus Zone against the decline of others
\end{abstract}

KEYwORDS: Public policy, Sectorial policy framework, Forestry, Parana Delta.

\section{INTRODUCCIÓN}

La actividad forestal puede ser señalada como uno de los subsectores agroindustriales que tempranamente y en forma continua ha sido objeto de programas de fomento económico y tecnológico por parte del Estado argentino. Los primeros antecedentes se registran durante la etapa de Sustitución de Importaciones (mediados de Siglo XX) con la formulación de leyes, organismos competentes, asignación de presupuestos específicos e instrumentos de fomento forestal e industrial basados en un sistema de créditos blandos y beneficios impositivos para el sector privado. Estas iniciativas eran justificadas en función de resolver un mercado interno insatisfecho de madera y papel; crear economías generadoras de empleo y divisas; así como la valoración positiva de la dotación de recursos naturales disponibles para la forestación. Dichos elementos que definen la cuestión forestal y legitiman la intervención estatal, se mantienen hasta fines de la década de los 90, momento en el cual se diseña la Ley Nacional 25080 de Promoción de Bosques Cultivados, actualmente en vigencia.

El desarrollo de las políticas sectoriales en el nivel general, y más aún en escalas locales, se constituyen en una temática escasamente analizada en la academia. Como parcialidad de las políticas públicas globales y en continua interacción con estas, se entiende por política sectorial aquella que restringe su campo de acción 
a un segmento socioeconómico con particularidades específicas. Nos interesa analizar la incidencia de estas en el Delta del Paraná Bonaerense, en donde se ha evidenciado un acelerado proceso de transformación socioeconómica que, de acuerdo a diversas investigaciones (Galafassi, 2000, 2002, 2004; Cobelo, 2005, entre otros), está vinculado con la expansión de la producción forestal a partir de la década de los 70 .

En este marco nos preguntamos, ¿̇cómo ha sido la evolución de la política sectorial forestal? ¿Qué aspectos son considerados para su diseño y aplicación teniendo en cuenta los variados contextos sociohistóricos por las que atraviesa? ¿Qué incidencia tienen los instrumentos de promoción sobre la configuración socioproductiva de los diferentes territorios donde son aplicados? Finalmente, el perfil forestal que se ha desarrollado en el Delta del Paraná, ¿es concurrente con la aplicación de dichas políticas forestales?

Estas preguntas se inscriben en dos líneas de investigación que se articulan en el objetivo general de comprender la incidencia de las políticas públicas en las transformaciones territoriales. La primera ${ }^{1}$ se aboca al análisis de las políticas públicas de aplicación en el espacio rural, teniendo como marco interpretativo que toda política lleva implícita una definición del problema, una representación del grupo social al cual se dirigen y una teoría de cambio social. A través de la noción de referencial desarrollada por Muller (2002) nos proponemos captar la cosmovisión contenida en las políticas públicas que, lejos de ser producto de consensos, acostumbra a ser la resultante de luchas y disputas que ocurren tanto dentro de la estructura del Estado y con distintos grupos de interés de la sociedad (Oszlak y O’Donnell, 1981). Dentro de ellas nos abocamos al estudio de las políticas forestales, que aunque en interacción con otros dominios de la acción pública, permite el análisis del inter-juego de intereses, las autonomías relativas y relaciones de poder entre los agentes de este sector económico específico en la definición de políticas, y por ende también la comprensión de la posición resultante por parte del Estado.

La focalización en lo forestal se inscribe en la segunda línea de investigación ${ }^{2}$ que se aboca al estudio del territorio del Delta Inferior del Río Paraná, más específicamente en la denominada Zona Núcleo Forestal. Esta región se caracterizó desde fines del siglo XIX por contener un modelo productivo diversificado y con cierta base en la horticultura y fruticultura sobre pequeñas explotaciones de trabajo familiar. Sin embargo, desde su auge en la década del 50 hasta su declinación en los 80, la competencia de otras regiones productoras, las dificultades de accesibilidad al mercado, las sucesivas inundaciones y la migración de una parte de su población en busca de una mejor calidad de vida, llevaron a la crisis de esa estructura agraria (Galafassi, 2002; Cobelo, 2005). Si bien la tradición forestal en el Delta encuentra sus primeros antecedentes a fines del siglo XIX (Borodowski y Suarez, 2004), es a partir de la década de los 70 cuando se expande un modelo productivo cuyas características distintivas son la escala de producción, la emergencia de productores e industriales empresariales y una especialización hacia la producción de maderas blandas y de papel, proceso denominado por Galafassi como forestalización (2004).

En este marco, el trabajo tiene por objetivos analizar el desarrollo del referencial de las políticas públicas a partir de la reconstrucción histórica de las regulaciones (leyes, decretos y resoluciones) e instrumentos dirigidos al sector de la producción forestal, e indagar la incidencia de las mismas en la (re)configuración socioproductiva de la región del Delta Inferior del Paraná hacia la forestalización.

\section{Marco CONCEPTUAL Y Metodológico}

Comprender las acciones del Estado, teniendo en cuenta la interpretación y producción de una problemática social que debe ser resuelta y la elección de los instrumentos destinados a resolverla, configura un campo de análisis en el cual confluyen diferentes perspectivas disciplinares. Muller (2002) y Surel (2008) se han abocado al análisis de estas a través del concepto de referencial, proyectando que el mismo cumple para los decisores de política pública una función similar a los paradigmas para la comunidad científica: un conjunto de valores, normas, visiones y representaciones de la realidad que estructuran su comportamiento. En el caso de los científicos esto toma la forma de un método y en el caso de los políticos el referencial toma la forma de una política pública determinada (Surel, 2008). En este marco, el referencial aduce a 
una imagen de la realidad social construida a través del prisma de las relaciones de hegemonía sectoriales y globales. Es una imagen codificada de la realidad. No obstante, esta imagen produce efectos tangibles: sin volver la realidad completamente transparente, puesto que ella oculta en general relaciones de hegemonía, la vuelve un poco menos opaca porque permite, a través de las normas que ella produce, actuar sobre la realidad (Jobert y Muller,1987, p. 70).

El estudio de la génesis de las políticas públicas distingue en una primera dimensión los principios metafísicos generales, definidos como aquellos que integran algunas indicaciones abstractas relativamente simples sobre los modos de funcionamiento de una sociedad y más específicamente del campo político. Son las imágenes que forman parte del referencial definido en el párrafo anterior y que implican un "proceso de categorización y definición de lo que es la realidad y que, en consecuencia, moldean las normas de acción más apropiadas" (Surel, 2008, p.45). Bajo un principio de diagnóstico y construcción del problema, es posible identificar hipótesis o razonamientos que vinculan ese universo simbólico con el universo más concreto, es decir aquello que permite operacionalizar los principios con generalizaciones formales que rigen en un determinado sector (Surel, 2008). El siguiente paso refiere al ejercicio práctico que articula las representaciones sobre la realidad con las generalizaciones adjudicadas al funcionamiento o a la composición sectorial y que establece tipos de relación (metodologías de acción) que existen o se consideren más apropiados entre el Estado y el sector bajo estudio, en este caso, el forestal. Este nivel de análisis abarca las relaciones de coerción, mediación y/o concertación que determinan las elecciones orientadoras de una determinada política y una caracterización de los actores concernidos. Los instrumentos y herramientas concretas completan el dispositivo global, es decir, la política pública. En el campo de la acción pública estos instrumentos son numerosos: discursos, leyes e instituciones específicas, así como su articulación con los actores del sector (Surel, 2008).

Bajo un abordaje metodológico cualitativo, el mapeo de los antecedentes de las leyes forestales en el país nos ha permitido en forma diacrónica indagar en los procesos sociales, políticos o administrativos que explican determinados elementos de los diagnósticos. A partir de lo anterior, se develaron continuidades y discontinuidades del/los referenciales de la política sectorial, que en definitiva ofrecen un marco más acabado de comprensión de los instrumentos de política así como de su impacto esperado y generado. Como sugieren Oszlak y O’Donnell (1981, p. 12) la observación en un contexto histórico determinado del conjunto de iniciativas y respuestas que constituye la política estatal, permite inferir la posición (predominante) del Estado frente a una cuestión que atañe a sectores significativos de la sociedad. De esta manera, es posible aproximarse al modo en que una política sectorial traduce el marco de las políticas globales a una porción de la sociedad, un sector que se rige bajo peculiaridades emergentes de los agentes que la componen, sus posiciones relativas en la distribución de capitales y de fuentes de poder. Dentro de esta esfera, centramos nuestra atención en los instrumentos de promoción financieros (tanto fiscales como monetarios) de fuentes nacionales que derivan en marcos regulatorios específicos, sin desconocer la incidencia de otras políticas como las socioambientales, las científico-tecnológicas, de tierras, de infraestructura y servicios, e incluso también financieras -como aquellas derivadas de fuentes de financiamiento internacional- que repercuten en el desarrollo del sector forestal.

La revisión de estudios, leyes e instrumentos en su contexto histórico se complementa con la realización de entrevistas en profundidad a funcionarios de la anterior Dirección de Producción Forestal de la Nación, a técnicos y a referentes de productores del sector forestal durante el 2015 y 2016 . El registro de las distintas ópticas de estos agentes contribuyó a la identificación de constituyentes del referencial sectorial en la actualidad, así como a la interpretación de determinados recorridos de los instrumentos de política pública en distintas etapas. Asimismo, la reconstrucción de sus perspectivas permitió enriquecer el estudio aproximativo de la incidencia de los instrumentos de política forestal en las últimas décadas en el Delta Inferior del Paraná, específicamente en la denominada Zona Núcleo Forestal (ZNF). Elaborado en base a revisiones 
bibliográficas y análisis cuanti-cualitativos (SIG y bases de datos) del Inventario Forestal Nacional realizado en la región bajo estudio, se ha caracterizado la distribución del apoyo técnico y financiero proveniente de la Ley de Promoción de Bosques Cultivados (Ley 25 080, vigente desde el año 1999) en función del tamaño de las unidades productivas beneficiadas. Finalmente, el análisis anterior nos permite reflexionar acerca del universo que se constituye como agentes destinatarios de las políticas públicas y sus capacidades individuales y asociativas para la apropiación de los beneficios de los instrumentos de promoción sectorial. De esta manera, apoyados en la perspectiva de análisis de Long, se busca comprender el modo en cómo "las intervenciones forman parte de una cadena o flujo de eventos localizados en una estructura más amplia de actividades de los cuerpos estatales y/o internacionales y las acciones de diferentes grupos de interés que operan en la sociedad civil" (2007, p. 78).

\section{TRAYECtORIA Y CARACTERÍSTICAS DE LAS POLÍticas DE PROMOCión FORESTAL EN Argentina}

Concluido en 1930 el modelo de desarrollo caracterizado por un país con un perfil productivo claramente agroexportador, comienza en Argentina otro modelo conocido por su orientación hacia la industrialización por sustitución de importaciones, donde el sector industrial comenzó a liderar el crecimiento de la demanda agregada, la producción y el empleo, desplazando al sector agropecuario hacia un lugar de menor relevancia. El modelo de industrialización sustitutiva de importaciones fue cobijado, aunque con diferencias sustanciales, por diferentes proyectos políticos desde entonces hasta su finalización en 1976. Dicho proceso es comprendido por algunos autores como un período de "industrialización inconclusa", que además estuvo caracterizado por un desarrollo desigual y asimétrico de la industria liviana y pesada, un país debatiendo la legitimidad y legalidad del peronismo y un contexto internacional convulsionado por la crisis del 29, la Segunda Guerra Mundial y el comienzo de la Guerra Fría. La reiteración de cambios estructurales en el comercio y en la economía internacional favorecieron un contexto tendiente a la protección parcial o total de la industria local (Ferrer, 2010).

En ese contexto y a partir del análisis de las normativas, se observa en nuestro país la generación más relevante de instrumentos de políticas para la promoción del sector forestal. Relevante porque, aunque hubo -como se demostrará más adelante-cambios y ajustes importantes en los instrumentos de promoción forestal, estos pivotearon en torno a un mismo objetivo planteado en las primeras leyes de promoción: el autoabastecimiento de madera para la producción de papel. Junto con el objetivo de fortalecer la producción local, convergió además en ese contexto el interés empresario por el desarrollo de la industria gráfica. Este último factor ha tenido incidencia en que el desarrollo de las políticas de fomento forestal tuviera inicialmente un sesgo hacia la producción celulósica y de papel, especialmente desde la década del 60 hasta fines del 70 . Fue también durante ese período que se desarrollaron grandes plantas industriales en sectores básicos, apoyados fuertemente por el Estado. Podemos citar como ejemplo a Propulsora Siderúrgica, Aluar, Papel Prensa y Papel Tucumán, Celulosa Puerto Piray, Petroquímica General Mosconi, Petroquímica Bahía Blanca, entre otras (Ferrer, 2010).

\subsection{LOS PRIMEROS PASOS}

¿Qué podría decir yo de nuevo en esta tierra en la cual estamos desde hace tantos años cantando nuestros deseos al árbol que esperamos? La República debe cubrirse de árboles, que demuestren que estos deseos, que hemos cantado tantos años, se conviertan en la voluntad inquebrantable de plantarlos, de cuidarlos y de utilizarlos para el bien de la patria. (Juan Domingo Perón, Cartilla Forestal del Ministerio de Agricultura y Ganadería, 1951) 
Durante el año 1946, bajo la presidencia de Juan Domingo Perón, se elabora el Primer Plan Quinquenal, cuyos objetivos se orientaron a activar todas las ramas de la producción con un conjunto de medidas específicas para cada sector productivo. Para el sector forestal se aprobó en 1948, la Ley 13273 para la "Defensa, Mejoramiento y Ampliación de Bosques".

También se crea la Administración Nacional de Bosques (ANB), que constituye el primer organismo público nacional destinado a la cuestión forestal. La ANB contenía una amplia gama de funciones tendientes a valorizar las masas boscosas. Estas abarcaban la defensa nacional en zonas de frontera, la protección del suelo, regularización del régimen de aguas, defensa contra la erosión e inundaciones, la formación de parques nacionales, la realización de estudios experimentales con especies nativas y fundamentalmente la producción y extracción periódica de productos y subproductos forestales.

De acuerdo a Zarrilli (2008) esta ley constituye uno de los principales antecedentes en materia ambiental que formula el Estado para la regulación del manejo de los bosques, la protección de los bosques nativos, con fines de protección y administración de los mismos (2008, p. 94). Sin embargo, en ella también se establecen las bases para la promoción económica del sector forestal, estableciendo mecanismos de beneficios como la exención de pago del Impuesto Inmobiliario, del Impuesto a los Réditos (hoy Impuesto a las Ganancias) y un régimen de créditos blandos financiados por el Banco de la Nación Argentina para aquellos que se dediquen a la actividad forestal. Con el paso del tiempo, las modificaciones introducidas y la producción de nuevas normativas tendieron a generar un sesgo más directo hacia la producción forestal con fines industriales.

Para la implementación de los créditos blandos se crea una estructura en la que participan la ANB y el Banco de la Nación Argentina. El primero se encargaba de definir, a través de su Consejo de la Administración, la orientación de la política de fomento. Mientras tanto, el Banco Nación se encargaba de administrar los créditos. La fuente de financiamiento para dichos créditos fue el Fondo Forestal, creado en la misma Ley 13273 a partir del cobro de aranceles a la importación de productos forestales. Si bien estos créditos estaban contemplados desde la aprobación de dicha ley, recién es en 1958 que se reglamentan mediante el decreto 4905/58.

Uno de los argumentos que caracterizan la proyección de la política forestal en esa época surge en el texto de dicho Decreto, planteando que:

el actual drenaje de divisas ocasionado por la importación de productos forestales, según estudios realizados por los organismos competentes, continuará en aumento en los próximos años, por lo que urge dar destino definitivo a los recursos que se obtengan por aplicación del Decreto-Ley $\mathrm{N}^{\circ} 861 / 58$, a fin de evitar dicha incidencia desfavorable para la economía general.

La aplicación de estos instrumentos continuó hasta mediados de la década del 70, aunque no se conoce el resultado en términos de incremento de superficie.

\subsection{DiFERENCIACIÓN SECTORIAL}

Durante el período desde el derrocamiento de Perón en el año 1955 hasta el año 1976, los ideales desarrollistas gravitaron fuertemente en las decisiones de política económica. El problema estructural que la Argentina atravesó desde 1930 hasta finalizada la década de 1990, y que persiste aún hoy de otra manera, fue el déficit estructural en la balanza de pagos, que provocaba sucesivas crisis y a las cuales se sumaba posteriormente el ajuste fiscal, la devaluación y el crecimiento de la deuda externa (Ferrer, 2010). Este déficit estaba producido según los desarrollistas por un problema de competitividad de la industria nacional, y su solución consistía en la incorporación del capital extranjero en el desarrollo de las industrias de base y en la explotación del petróleo. A inicios de la década del 70, Argentina ocupaba el primer lugar en América Latina en consumo de diarios y revistas, e importaba casi la totalidad del papel que consumía. Esto implicaba una erogación en divisas de más de 100 millones de dólares anuales, entre papel y pasta celulósica (Getino, 1995). La producción nacional 
de papel prensa era un anhelo largamente deseado por los diarios nacionales y, de concretarse, conformaría un gran beneficio económico para sus balances, así como posiblemente una mayor autonomía con relación al poder político (Borrelli, 2008). Sin embargo, como argumentan Lajer y Tempestoso en su estudio sobre el desarrollo del complejo celulósico-papelero, hubo que esperar treinta años para el primer paso firme hacia la sustitución con la puesta en marcha de Papel Prensa SA. Las razones de ello se pueden aducir al importante volumen de inversión requerido, al tiempo necesario para alcanzar un nivel suficiente de aprovisionamiento continuo de materia prima -dependiente de la actividad forestal-, así como también a la resistencia de los periódicos de gran tirada en el país (2010, p. 18).

Tras la muerte del fundador del diario Clarín (Roberto Noble) en 1969, asume la dirección Ernestina Herrera de Noble, quien con importantes vínculos políticos, se constituye hasta 1975 en una figura influyente desde la conducción del diario. Ese mismo año (1969), el gobierno de Onganía aprueba la Ley 18.312 para la creación del "Fondo para el desarrollo de la producción de papel prensa y de celulosa", el cual tenía como objetivo la realización de un concurso para un estudio de viabilidad y posterior construcción de una planta de papel prensa. Finalmente, en 1978 se concretó el acontecimiento más importante para la historia de la prensa nacional: la inauguración de la planta productora de papel para diarios de la empresa Papel Prensa SA, de la cual fueron beneficiados como accionarios los diarios La Nación, Clarín y La Razón junto con el Estado que mantuvo el $25 \%$ de las acciones. La planta, ubicada en la margen derecha del Paraná al sur de San Pedro, contó con una inversión de 62 millones de dólares (Borrelli, 2008).

Así, con la perspectiva de sumar una gran boca de consumo forestal como Papel Prensa SA, se crea en 1973 el Instituto Forestal Nacional (IFONA) mediante la Ley 20531 y se reglamenta en el año 1974 (Decreto 465/74) un beneficio de desgravación impositiva para productores forestales.

La creación del IFONA significó una renovación de los lineamientos establecidos en la Ley de Defensa de la Riqueza Forestal de 1948. Por primera vez se declara de interés público la promoción de la industria forestal y entre las atribuciones del nuevo organismo están la de intervenir el mercado, reglamentar el tráfico de productos, instalar aserraderos, crear centros de investigación y ejecutar todo lo que respecta a las políticas de promoción forestal. Otro paso fue la incorporación por ley de la Asociación Forestal Argentina (AFoA) a la Comisión Asesora del IFONA, institución que cobrará protagonismo durante el proceso de elaboración de la ley actual de promoción forestal.

Al finalizar el año 1977, la dictadura cívico-militar aprueba la Ley 21695 de Crédito Fiscal para la Forestación, sustituyendo de esta manera el régimen de promoción anterior basado en la desgravación impositiva sobre el impuesto a los Réditos (Sánchez Acosta y Vera, 2005). El mecanismo establecido por dicha ley fue otorgar certificados que podían ser utilizados para cancelar cualquier impuesto a cargo de la Dirección General Impositiva (DGI). El valor del certificado se establecía en base a los costos de las labores requeridas para la plantación y el cálculo de los mismos estaba a cargo del IFONA, que los expedía anualmente en función del grado de cumplimiento de las tareas programadas para el año. Este mecanismo permitía al beneficiario convertir el valor del certificado en dinero por un equivalente al $95 \%$ de su valor nominal. Según un funcionario técnico (Entrevista n. ${ }^{\circ}$ 5, 2015: Funcionario de la Dirección de Producción Forestal), "los beneficiarios retiraban por una ventanilla del Banco Nación el certificado y lo canjeaban por dinero efectivo en otra ventanilla". Como señala Zarrilli (2008) la ley contenía en su formulación un defecto adicional, que era que otorgaba créditos sobre la base de la planificación de plantaciones y no sobre plantaciones logradas. Ambos factores permiten observar que, si bien esta ley estuvo diseñada para alentar a nuevos inversores, en su operatoria significó el primer antecedente de una transferencia al sector privado involucrando importantes eventos de evasión impositiva.

Bajo esta ley, cuyo enfoque estuvo dirigido a proveer de materia prima a la industria de trituración con destino a la fabricación de pasta celulósica, la superficie forestada se incrementó en 388108 ha, y la misma puede ser considerada como la primera que permitió tener un resultado relevante sobre la expansión de la superficie forestada. 
Por último, la capitalización de la masa forestal producida en virtud del aumento de peso de la plantación, estuvo exenta del pago de cualquiera de todos los impuestos de índole nacional (Art. 14, Ley 21 695, 1977).

\subsection{Régimen de Promoción de Plantaciones forestales}

Luego del golpe de Estado en 1976 y hasta el año 2001 Argentina vivió un período cuyo patrón de acumulación económica se orientó fuertemente hacia la industria de servicios y el sector financiero. Las políticas de desregulación del Estado en la actividad económica se comenzaron a implementar durante el gobierno de la Junta Militar y se profundizaron ya en democracia durante el gobierno de Carlos Menem (Ferrer, 2010).

En este marco, en 1991 se aprueba el Decreto 2284 para la desregulación económica, donde entre otros organismos se disuelve el IFONA. Transcurridos más de diez años desde la aplicación de la Ley de Crédito Fiscal para la Promoción Forestal en 1977, se implementa el "Régimen de Promoción de Plantaciones Forestales" conocido como RPPF. Dicho régimen fue aprobado a través de la Resolución 778 de 1992 e implicaba la entrega de subsidios por parte del Estado Nacional a los que presentaran "planes forestales", iniciando de esta manera la fase de apoyo al sector forestal basado en la transferencia directa, mediante "beneficios" i.e. aportes no reintegrables. Entre los fundamentos del instrumento, se reafirman los elementos del referencial de esta política sectorial, al manifestar:

i. la gran importancia de la actividad forestal para el desarrollo del país, ii. que existen buenas perspectivas en los mercados internacionales para los productos forestales, iii. que existe una gran aptitud ecológica en grandes regiones del país para la producción forestal [y por lo anterior] iv. que es conveniente la contribución del Estado para concurrir la promoción de las plantaciones forestales (Norma 29 976/1993).

Con esta normativa se definen dos aspectos de significancia para el presente análisis. Los destinatarios se categorizan en dos grupos, las medianas y grandes empresas y los pequeños productores, estableciéndose criterios de distribución regresivos del fondo nacional destinando el $74 \%$ del presupuesto total a la primera categoría y el $25 \%$ a la segunda. Adicionalmente, para las medianas y grandes empresas se priorizaban a los titulares de los planes aprobados técnica y legalmente, cuyas solicitudes presentaran el menor monto por hectárea forestada, dando prioridad al plan de forestación que proponga realizar la mayor superficie hasta un máximo de 700 ha. En cambio, para los pequeños, si bien se mantiene el criterio de menores costos por hectárea y la aprobación legal y técnica de los planes, se priorizaban aquellos que soliciten menores superficies a subsidiar hasta un mínimo de 2 ha. El segundo elemento que deseamos destacar es la identificación de las regiones de mayor aptitud para el desarrollo de la forestación, con lo cual se establecen en la Ley las zonas prioritarias (aunque no excluyentes) a recibir el fomento, luego consideradas como núcleos forestales.

Para la implementación del RPPF se crea en 1993 la Dirección de Producción Forestal (DPF) en el ámbito de la entonces Secretaría de Agricultura, Ganadería y Pesca de la Nación (SAGPyA).

En el año 1997 adicionalmente se sanciona la Ley $N^{\circ} 24857$ (Ley de Estabilidad Fiscal de la Actividad Forestal) de orden impositivo, estableciendo que, por el término de 33 años, todas las empresas que desarrollen actividades forestales orientadas a la implantación y manejo de bosques cultivados o naturales en áreas de aptitud forestal, no podrán ser afectadas en su carga tributaria total por aumentos en las contribuciones impositivas y tasas en los ámbitos nacional, provincial o municipal vigentes al momento de la presentación del estudio de factibilidad respectivo. De esta manera, se complementan los instrumentos tributarios en forma específica para el sector forestal.

Si bien no se cuenta con datos del impacto por regiones y/o categoría de forestadores, bajo este régimen se llegó al récord de superficie plantada anualmente desde 1948 hasta la actualidad: 113226 ha sólo en el año 1999 y con un total de 372347 ha durante el período de 1992 hasta 1999 (ver Figura 1). 


\subsection{LA LEY 25080}

En 1998 se sancionó en el Congreso de la Nación la "Ley de Inversiones para Bosques Cultivados" (25 080) con el objetivo de promover la producción forestal. Dicha ley se implementó mediante el decreto 133/99, donde se incluyen importantes definiciones sobre su instrumentación. Vale destacar que con esta Ley se circunscribe el carácter sectorial de las plantaciones cultivadas, diferenciándose de aquellos instrumentos de protección y/o promoción de usos maderables de bosques nativos ya existentes.

Bajo este marco se preveía incrementar la superficie forestada en un lapso de 10 años a 2 millones de ha, es decir el doble que la superficie contabilizada en 1998. El mecanismo de estímulo consistía nuevamente en la entrega de un aporte no reintegrable (ANR) y un régimen especial de beneficios fiscales a quienes efectúen nuevos emprendimientos forestales y a quienes habiendo desarrollado uno con anterioridad, decidan ampliar la dimensión del mismo con el fin de incrementar la oferta maderera. De esta manera se reactualiza el objetivo general de aumentar la oferta maderera a través de la implantación de bosques y beneficiar la instalación y/ o ampliación de proyectos foresto industriales.

Dichos ANR eran girados por el Estado Nacional a través de la SAGPyA (definida como Autoridad de Aplicación) y actualmente por el Ministerio de Agricultura, Ganadería y Pesca (MAGyP) junto con el Ministerio de Economía. Los ANR están sujetos al criterio de escala de emprendimiento: entre 1 y 300 ha, se subsidiará hasta el $80 \%$ de los costos de implantación; y entre 301 y 500 ha, se subsidiará el 20\% de los costos de implantación. Se incorpora como innovación en esta Ley la contabilización de las labores forestales (poda, raleo y manejo del rebrote), costos que gravitan significativamente en el capital inmovilizado de los productores forestales. El régimen de Estabilidad Fiscal ${ }^{3}$ continúa y podían acogerse los beneficiarios de esta ley, sin restricciones en cuanto a la dimensión del emprendimiento forestal.

El Decreto Reglamentario 133/99 en el artículo 18 especifica la figura de pequeño productor como aquel que tiene vivienda permanente en el predio a forestar, utilice mano de obra familiar y obtenga la mayoría de sus ingresos a partir de su emprendimiento forestal. A partir de estas características se le otorga el derecho de recibir el 50\% de la ayuda económica al momento de aprobarse el proyecto y el resto contra certificación de tareas. Esta definición es distintiva para las leyes anteriores, en las cuales los sujetos beneficiarios eran definidos ampliamente como personas físicas o jurídicas que realicen efectivas inversiones, empresas o productores de diversos estratos sin especificar sus características en cuanto a dotación de capitales, limitando el aporte crediticio o no reembolsable por la cantidad de ha totales. No obstante, durante la aplicación de la ley, la figura del pequeño productor es suplantada por la figura del pequeño forestador, perdiendo peso la condición socioeconómica del destinatario de los ANR y primando como criterio la superficie presentada por el plan a ser subsidiado. En términos de un técnico entrevistado durante 2015 (entrevistado 6, 2015), en relación a la identificación como pequeño productor planteaba: "Para nosotros la vara es la superficie. Si viene Bill Gates con 5 ha, entonces es un pequeño productor".

Las dificultades de acceso a los instrumentos de promoción forestal por parte de los pequeños forestadores han recibido diferentes tipos de respuesta desde las autoridades de aplicación. Los antecedentes más sustanciales se produjeron desde la implementación del RPPF, dado que los pequeños productores tuvieron la posibilidad de presentar planes forestales de manera agrupada. Dicha estrategia implicaba la intervención de una entidad de bien público o de un gobierno municipal que representara a los pequeños productores y se encargara de recibir por adelantado una parte del pago correspondiente a la sumatoria de la superficie de todos los productores. Con esta herramienta se preveía que los pequeños productores tengan la suficiente liquidez financiera inicial para poder comprar los insumos y realizar las labores de preparación y plantación. El pago final que se realizaba a "plantación lograda", estaba sujeto al desempeño de todos los miembros del grupo y se distribuía de manera equitativa entre todos ellos. No obstante, el desempeño diferencial de cada miembro de un mismo grupo así como la complejidad en el funcionamiento de las entidades de representación de los pequeños productores trajo consigo conflictos, y esta herramienta de "Planes Agrupados" no funcionó, 
representando en el ejercicio de la ley entre 2003 y 2016 apenas un $4 \%$ de los sujetos beneficiados (Entrevista n. $\left.{ }^{\circ} 4,2015\right) .^{4}$

Durante el período de implementación de esta ley la superficie forestada se incrementó más de 530.000 ha en todo el país. Según los datos actualizados a 2016, las estadísticas publicadas por la Subsecretaría de Desarrollo Foresto Industrial (DFI, antes DPF) del Ministerio de Agroindustria, el fondo nacional destinado para la Ley 25080 financió desde 2003, y a través de ANR, cerca de un millón de ha forestales para la implantación y tareas de manejo de plantaciones existentes, con un monto de 1040 millones de Pesos Arg. ${ }^{5}$

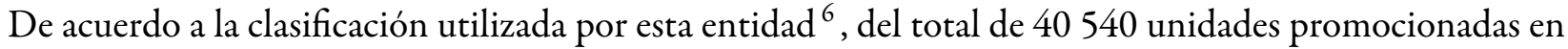
toda la Argentina, el 17\% corresponde al estrato "grandes forestadores". Estos recibieron el 83\% del fondo destinado a la promoción forestal y aportaron con un $82 \%$ a la superficie forestal promovida. En cambio, los pequeños forestadores, los pequeños agrupados y las comunidades indígenas representaron el 83\% del universo y el $17 \%$ del monto destinado. Si bien varía entre provincias, la distribución de los beneficios de la Ley mantiene el patrón nacional, siendo en el caso de la provincia de Buenos Aires menos concentrado: el $48 \%$ de los que se acogieron a la Ley eran grandes forestadores y recibieron el $86 \%$ de los fondos de ANR; mientras que la porción restante corresponde a pequeños forestadores individuales con el $46 \%$ y $8 \%$ para los agrupados. Estos dos últimos recibieron el 14\% del monto destinado a la provincia.

En la Figura 1, se grafica el crecimiento por año promovido por cada uno de los regímenes de promoción forestal aplicados entre 1978 y 2013.

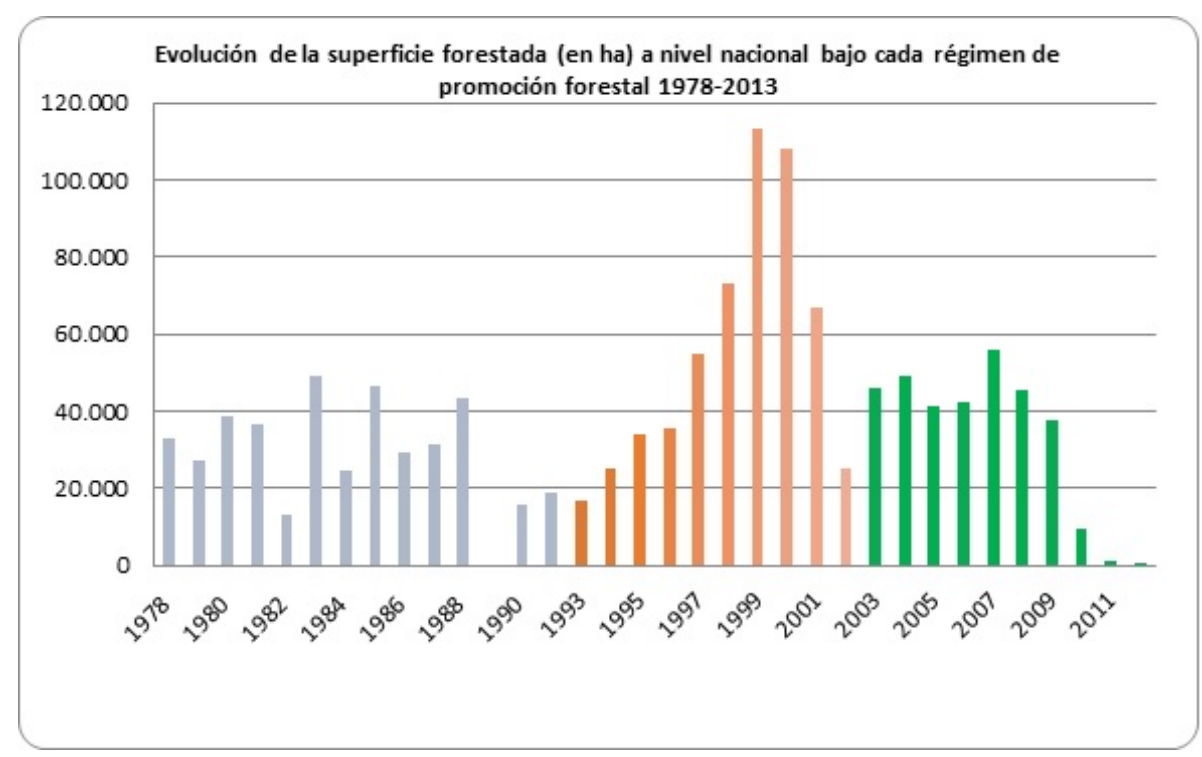

Figura 1. Evolución de la superficie forestada a nivel nacional bajo cada régimen de promoción forestal Fuente: Sánchez Acosta y Vera (2005) y elaboración propia en base a datos suministrados por la Dirección de Producción Forestal (2015).En celeste la evolución correspondiente al crédito fiscal, en rojo al régimen de promoción de plantaciones forestales y en verde al régimen promoción de inversiones para bosques cultivados. Los datos desde 2010 aún están en proceso de elaboración.

Desde el año 1978 hasta 2011, se promovieron 1.290 .455 ha forestales. Esto fue el resultado de la aplicación sucesiva de tres regímenes: Crédito Fiscal (388 108 ha); RPPF (372 347 ha); Ley 25080 (530 000 ha). El promedio anual (1978 - 2011) fue de 37931 ha y la superficie máxima fue 113226 ha en un solo año (1999).

Si bien los modelos de desarrollo del sector forestal en nuestro país no han sido lo suficientemente estudiados, se observa una cierta continuidad en cuanto a la visión predominante que fundamentó los instrumentos de promoción. Los objetivos de política industrial para el sector forestal consisten básicamente en el incremento de la superficie forestada a los fines de abastecer la industria local y generar economías de escala suficientes para la instalación de industrias nuevas, principalmente celulósicas (Valtriani, 2008). Mientras tanto, en el resto de Latinoamérica (especialmente Uruguay y Chile) no ha sido diferente el tipo 
de instrumentos utilizados a lo largo de la historia para promover esta actividad: aportes reintegrables y no reintegrables para expandir la superficie forestada y beneficios impositivos para las empresas forestoindustriales.

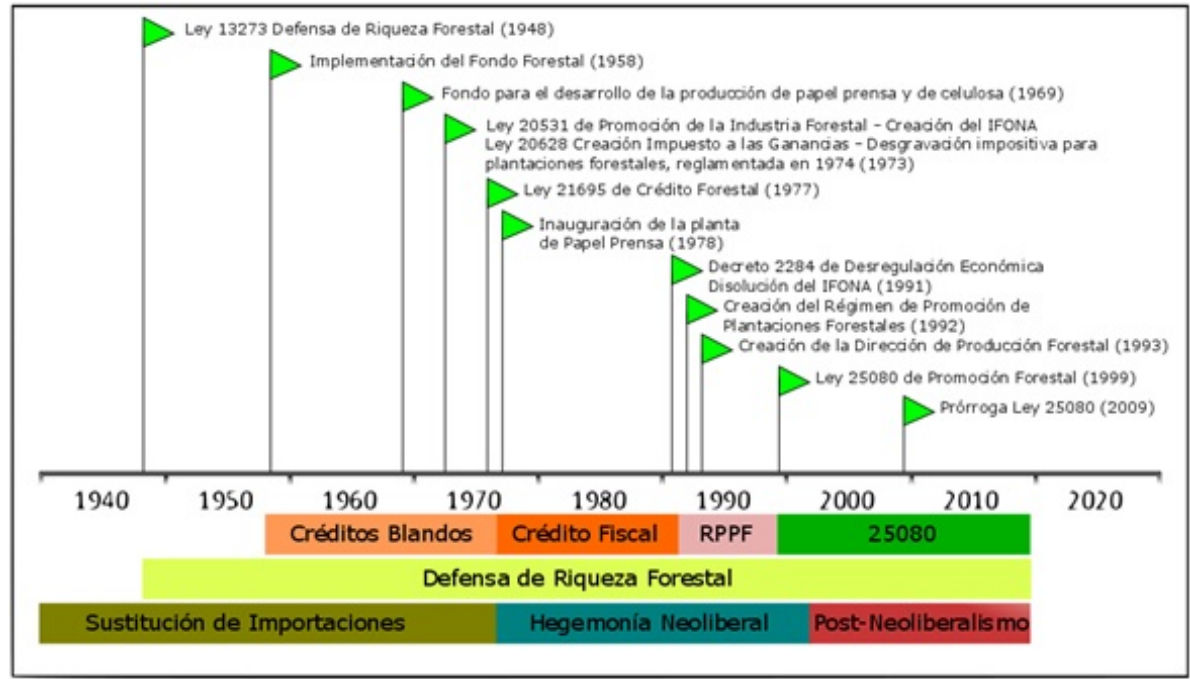

Figura 2. Etapas en los instrumentos de promoción forestal en el contexto histórico nacional Fuente: Elaboración propia. En el gráfico se muestran los diferentes instrumentos de promoción forestal así como el período de vigencia de la Ley de Defensa de la Riqueza Forestal a lo largo de los diferentes períodos históricos, y algunos hitos importantes en el desarrollo de las políticas de promoción forestal en Argentina.

\section{UNA APROXIMACIÓN AL REFERENCIAL DE LA POLÍTICA SECTORIAL FORESTAL}

A partir del modelo de industrialización por sustitución de importaciones, hasta la etapa actual, se observan ciertas continuidades y discontinuidades por parte del Estado en la política de promoción hacia el sector forestal. Para su análisis, se han identificado un conjunto de supuestos que participan de la problematización sectorial y que, de acuerdo a la interpretación histórico contextual, configuran las bases para el diseño de leyes, instrumentos y sus modalidades de implementación. De esta manera se busca comprender la dimensión cognitiva del modelo de referencia, que debe proporcionar los elementos de las interpretaciones de las fuerzas que determinan la evolución probable del sector y la sociedad, la dimensión normativa definiendo los valores a través de los cuales habrá que asegurar esa evolución esperada y por último la dimensión instrumental a partir de un conjunto de principios que orientan la acción pública (Jobert y Muller, 1987). La identificación de los agentes públicos y privados y qué intereses se negocian y se imponen en esta arena sectorial, permitirá iluminar la orientación de las políticas públicas y la elección de los instrumentos de promoción sectorial, aproximación que fue posible realizar mediante el desarrollo de entrevistas a referentes del sector en relación con la discusión de la Ley 25080 formulada en el año 1998 y en vigencia.

\subsection{SuPUESTOS PARA UN REFERENCIAL SECTORIAL}

A continuación se presentan los supuestos identificados a través del análisis histórico contextual y de las entrevistas:

1. La Argentina tiene un mercado interno insatisfecho respecto a madera y pasta para papel y por consiguiente debe importar.

2. El incremento en la producción forestal mejora la balanza comercial del país. 
3. La formación de masas forestales predispone la instalación de nuevas industrias de base forestal y estas generan empleo.

4. La gran dotación de recursos naturales de Argentina, en particular, tierras aptas para forestar, es la base potencial del desarrollo del sector.

5. Las plantaciones forestales requieren altas inversiones de capital y de largo plazo.

Los primeros tres supuestos soportan el escenario deseado de la política forestal hacia el desarrollo de un saldo comercial positivo, y posicionando al país como proveedor de materias primas forestales así como algunos productos de la foresto-industria local, en particular provenientes del segmento celulósico. Estos elementos son arrastrados desde las primeras leyes forestales y también se encuentran presentes en la Ley 25 080, sancionada en el año 1999, en cuya carta de presentación se señalaba como objetivo general

consolidar el desarrollo foresto-industrial argentino, de manera tal que pueda convertir al sector en un generador significativo y visible de riqueza genuina, que cree una base de recursos leñosos de alta calidad y competitividad con destino a una industria transformadora moderna y relevante.

En los lineamientos estratégicos del Plan de Inversiones 2020 realizado por el Ministerio de Ciencia, Técnica e Innovación Productiva de la Nación (MINCyT), se destaca el histórico y creciente déficit de la balanza comercial forestal de la Argentina, señalando que aún en el año 2010 la exportación argentina de productos forestales alcanzó los 1.105 millones de dólares, mientras que la importación fue de 1.700 millones de dólares de los cuales el 59\% corresponde al rubro "Papel y Cartón" (MINCyT, 2013).

En estos supuestos se apoyaron sectores del Estado para legitimar su intervención directa en la promoción del sector a través de estímulos económico-financieros para el ámbito privado. Los instrumentos diseñados comenzaron con una matriz de financiamiento basada en créditos blandos y evolucionaron en mecanismos de transferencia directa hacia el sector mediante aportes no reintegrables. En este cambio se evidencia no sólo un análisis de resultado del estímulo de cada instrumento sino también disputas ganadas por las corporaciones sectoriales en la mesa de negociación público-estatal. El segundo instrumento tradicional, y que no ha sufrido importantes variaciones, es el de reducción de las cargas impositivas a través de los regímenes de estabilidad fiscal y otros recursos, tanto para la atracción de inversiones primarias como del sector industrial. Por su parte, el involucramiento del Estado Nacional como agente activo productor -en connivencia con intereses del sector privado-, se expresó en grandes emprendimientos como la creación de Papel Prensa en la década de los setenta y en el nivel provincial de empresas público-privadas de manejo de tierras fiscales forestales. ${ }^{7}$

Respecto a la dimensión ambiental y productiva en la Argentina, los instrumentos de las leyes forestales sufrieron ciertas variaciones en el referencial consecuentes al desarrollo de estrategias de conservación y fomento de los bosques, la valoración de los mismos en cuanto a su origen (nativos e implantados) así como a su ubicación en zonas estratégicas como las zonas de frontera y cuencas. Si bien se mantuvo la visión de las buenas y extensivas condiciones agroecológicas en la Argentina para la actividad forestal, la identificación de regiones con altos potenciales ecológicos para el desarrollo de bosques cultivados generó estrategias de focalización (región mesopotámica, patagónica, bonaerense) para el fomento estatal de especies exóticas de rápido crecimiento y/o calidad de madera. Sin embargo, estas focalizaciones fueron disputadas por los gobiernos provinciales, diluyéndose y dando lugar a una potencial cobertura nacional de acuerdo a las propuestas provinciales. En este marco, la creación del Consejo Federal de Medioambiente (COFEMA) en 1990 contribuyó a federalizar las discusiones relativas a la aplicación de las normativas ambientales y productivas. Conforme la instalación de la cuestión ambiental en la Argentina y su posterior formalización institucional en organismos del Estado nacional y provincial, la diferenciación entre bosque implantado y nativo derivó con el tiempo en regulaciones específicas para cada uno, mientras que se incorporaron instrumentos de control de impacto ambiental en los primeros. Debe destacarse que a partir del 2008 rige la Ley de Presupuestos Mínimos para la Protección Ambiental de Bosques Nativos (Ley 26331) siendo su autoridad de aplicación la Secretaría de Ambiente y Desarrollo Sustentable de la Nación (actualmente con 
rango ministerial), donde se encuentra la Dirección de Bosques Nativos. De la implementación anterior resultó que la aprobación de los expedientes de la Ley 25080 fue restringida hasta tanto cada una las provincias aprobara su ordenamiento territorial ${ }^{8}$ de bosques nativos y garantizara que las nuevas plantaciones forestales subsidiadas no ocupasen el lugar de los mismos.

Finalmente, el supuesto basado en el alto nivel de inversión, plazo de retorno e incertidumbre económica de la actividad forestal, adquiere un peso gravitatorio en el referencial sectorial. De ello deriva la concepción de la forestación -y particularmente la industrial- como una economía de escala, en la cual a medida que la producción en una empresa crece, sus costos por unidad producida se reducen hasta un nivel óptimo. Por un lado, aspectos técnicos de la producción plantean restricciones significativas como el turno de corta de al menos 8 años en el menor de los casos, llegando a ser de varias décadas en especies sin mejoramiento genético. La inversión en infraestructura para la producción, de acuerdo a las regiones, es otro elemento clave, tal como lo representan las obras de ingeniería en endicamientos en la región del Delta del Paraná. Bajo este supuesto del referencial, el sujeto privado destinatario de los incentivos estatales para la forestación se constituyó en el mediano a gran productor, el empresario, o inversionista externo, mientras que en la letra de los instrumentos legales emergía en forma genérica como productor o forestador. Es recién a partir del Régimen de Promoción de Plantaciones Forestales y luego en la Ley 25080 que se incorporan medidas diferenciadoras por estratos, definiendo al pequeño productor forestal como parte del universo atendible por estos instrumentos.

Lo anterior se comprende contextualmente en la década de los noventa, con la emergencia de diversos programas de desarrollo rural orientados a pequeños productores y campesinos. De acuerdo con Lattuada (2014), el tema del desarrollo rural se instala definitivamente en la Argentina cuando se diagnostica que la mitad de las explotaciones agropecuarias del país desaparecerían, incluyendo buena parte de los pequeños y medianos productores de la región pampeana, bajo las condiciones del nuevo modelo de paridad cambiaria, apertura y desregulación de la economía (2014, p. 20). En este marco, las iniciativas para el sector forestal no podrían eludir formalmente la inclusión del pequeño productor como destinatario en sus instrumentos. Por otro lado, provincias tradicionalmente forestales como Misiones, que se caracterizan por una alta proporción de pequeños productores en continua tensión con las grandes empresas foresto-industriales (Manzanal, Arzeno y Nardi, 2011), comienzan a ser consideradas en el ámbito de negociación pública. ${ }^{9}$ En este contexto, sumado a críticas de orientación de los tradicionales formatos de fomento forestal hacia el sector empresarial, se incorporan instrumentos específicos para los productores pequeños, acompañando la generación de programas de desarrollo rural orientados a esta población.

\subsection{ESPACIOS DE NEGOCIACIÓN Y CRISTALIZACIÓN DEL REFERENCIAL SECTORIAL}

En el marco de la elaboración de la Ley 25 080, se generaron espacios de concertación y acuerdos convocados por un asesor del entonces Secretario de la SAGPyA en 1998. Se constituyó para ello una Comisión Asesora compuesta por: Asociación Forestal Argentina (AFoA), Federación Argentina de la Industria Maderera y Afines (FAIMA), Asociación de Fabricantes y Representantes de Máquinas, Equipos y Herramientas para la Industria Maderera (ASORA), técnicos de las universidades y del INTA y representantes de las provincias. Su objetivo fue el de definir los lineamientos de la ley forestal y luego realizar el seguimiento de la implementación de la misma.

En dicho ámbito se comenzó a discutir el proyecto de ley a partir de una primera propuesta borrador, que, de acuerdo a las entrevistas ${ }^{10}$, fuera presentada por AFoA. Dicha Asociación, que representa los intereses de los medianos y grandes productores, así como de las empresas forestales, es gravitante dentro del sector forestal y sus representantes se autoidentifican (adjudicándose por ejemplo la letra de la ley actual y su participación en anteriores) como uno de los principales interlocutores entre las autoridades y técnicos del gobierno y los productores y empresas de base forestal. 
La Comisión Asesora también ofició como espacio de intercambio y catalizadora de tensiones para que los representantes de las provincias puedan tener incidencia en el proceso de formulación de la ley. De ello resulta que la propuesta inicial de fomento enfocada en las denominadas Zonas Núcleo Forestales como continuidad del régimen de promoción forestal anterior, se modifica hacia una propuesta de ley con alcance nacional. Es decir, cualquier provincia, tuviera o no desarrollada una economía forestal, podría adscribirse en esta ley. En dicho proceso, interviene otro factor que es el traspaso a los Estados provinciales de la potestad sobre los recursos naturales a partir de la reforma constitucional del año 1994. Bajo este tipo de ordenamiento jurídico, las provincias tenían la obligación de dictaminar sobre la viabilidad de cada proyecto presentado en función de una zonificación y ordenamiento establecidos a los fines de proteger las superficies con bosques nativos y no reemplazarlas con bosques cultivados (responsabilidad que a partir de 2008 se plasma en la Ley de Presupuestos Mínimos para la Protección Ambiental de los Bosques Nativos).

La composición de la Comisión fue un factor muy importante en la definición de los modos de implementación de la Ley 25 080. Respecto de la presencia de entidades colectivas es interesante rescatar de las entrevistas que, si bien las asociaciones de pequeños productores forestales fueron convocadas, las mismas tuvieron una participación discontinua en dicho ámbito, constituyéndose AFoA como interlocutor privilegiado de los intereses del sector en la mesa de negociación con el Estado. Esta relación puede ser analizada como un tipo de mediación corporativista, es decir un arreglo mutuo en el cual el Estado pretende estabilizar el ámbito social de una política pública, asignándole a uno de los actores un papel prominente, lo que le permitirá a su vez disponer de un punto de apoyo alternativo y eficaz en el sector. Por su parte la organización se garantiza un lugar en el espacio de la elaboración de las políticas públicas que afectarían su grupo de interés (Muller, 2000, p. 56).

Desde el diseño e implementación de la Ley 25.080 hasta la actualidad, se configuraron un conjunto de peticiones regulares por parte de AFoA hacia las autoridades del MAGyP que nos permiten referirnos a un tipo de relación político-institucional que presenta tensiones y acuerdos. A instancias de los primeros borradores, la Ley Forestal de Chile ${ }^{11}$ constituía un modelo para adaptar en la Argentina, en particular en lo referente a la bonificación económica de las superficies forestales sin límite alguno de la superficie que ocuparan. Esta propuesta de acuerdo a las entrevistas no fue aceptada por el Ministerio de Economía y Finanzas, y en cambio se constituyeron límites para acceder al subsidio de ANR, estratificando los beneficios por escala del emprendimiento forestal. Según uno de los referentes nacionales de AFoA (Entrevista n. ${ }^{\circ} 2$, 2014) luego las peticiones para la fase de implementación contemplaron especialmente incidir en: mejorar la velocidad con la que se cobra el subsidio; aumentar la disponibilidad de presupuesto para pagar los expedientes pendientes de cobro e implementar mecanismos adecuados para la promoción de la industria forestal.

AFoA, creada en la década de los 40, podría identificarse con una nueva generación de entidades corporativas rurales (Blacha y Magallán, 2015), cuyo perfil se orienta a posicionarse a partir de su conocimiento experto y lógicas y prácticas productivas identificadas con el agronegocio (Gras y Hernández, 2013). Un elemento central que las distingue es la innovación y difusión de los paquetes tecnológicos aplicados (Cáceres, 2015), para lo cual recurren a alianzas con organismos públicos y privados en el campo de la investigación y la extensión. Una modalidad es a través de la participación en congresos científicos sectoriales, la cual le permite no sólo la difusión de los nuevos modelos tecnológicos, sino también incidir en las agendas de las universidades y agencias científico-técnicas para incorporar líneas de investigación orientadas a resolver sus propios desafíos técnicos y económicos. En forma similar a AAPRESID y a ACREA para el sector agrícola y ganadero, AFoA es coorganizador de diversos congresos científicos y su vez trabaja activamente con INTA en la aplicación y difusión de las innovaciones tecnológicas (protocolos de buenas prácticas e incremento en la oferta de clones). En definitiva, a diferencia de las organizaciones tradicionales como la SRA, CONINAGRO o CRA, estas corporaciones construyen una capacidad de agencia con una base menor en el reclamo gremial, pero disputando su participación en el campo político sectorial a través de su 
rol asesor y promotor destacando su experticia técnica y organizacional, además de la envergadura económica y financiera que aglutinan corporativamente. ${ }^{12}$

\section{Incidencia de la política forestal en el Delta Inferior del Paraná}

Dentro del Delta Inferior del Paraná Bonaerense la región forestal por excelencia es conocida como Zona Núcleo Forestal (ZNF) y se especializa en la producción de salicáceas: sauces y álamos. La ZNF está delimitada por el Río Paraná al Sur, la Ruta Nacional n. 12 (Puente Zárate Brazo Largo) al Oeste, el Río Paraná Guazú al Norte y los canales 4 y Gobernador de la Serna al Este, ocupando un área de 90745 ha. ${ }^{13}$ Abarca la parte insular del Municipio de Campana y una porción insular del Municipio de San Fernando. Dadas las características ecológicas de la región y debido a las inundaciones que se producen periódicamente, el desafío de mantener niveles de control hídrico dentro de los predios agropecuarios ha sido una preocupación histórica que resultó en la instalación de sistemas de diques, albardones y terraplenes. ${ }^{14}$ No obstante, es a partir de la década de los 70 que se observa un proceso de mayor inversión e incorporación de diques a los sistemas productivos, lo que también convergió con un incremento en el tamaño de los establecimientos, una mayor especialización en la actividad forestal y la aparición de grandes productores, algunos de ellos con un perfil claramente empresarial (Galafassi, 2004). ${ }^{15}$ Conforme este proceso, también se desarrollaron algunas estrategias asociativas para favorecer la organización interempresarial y la economía de escala entre pequeños productores, destacándose por ejemplo la creación del Grupo Carabelas en 1981 y otros grupos asociativos fomentados por el INTA tanto en Delta como en otras regiones del país. ${ }^{16}$ No obstante, esta mayor especialización forestal sería acompañada por una disminución sustancial de la población isleña (Olemberg, 2014), dado que en el año 1982 se genera una de las mayores crecidas del río Paraná generando fuertes pérdidas productivas, la desarticulación del modelo fruti-hortícola tradicional local y un proceso de emigración de familias afectadas por las inundaciones (Galafassi, 2000; Pizarro, Moreira y Ciccale Smit, 2013).

De acuerdo a las entrevistas realizadas, la Ley de Crédito Fiscal para la Promoción Forestal de 1977, y las facilidades impositivas de ese período, favorecieron la instalación de empresas de capitales extra sectoriales y la expansión de unidades locales en la región que encontraban su oportunidad tanto en los beneficios fiscales así como en la incorporación de más tierras para la producción debido a la crisis de la fruticultura y la emigración de pequeños productores. Impulsados por el efecto de la instalación de Papel Prensa en el año 1978, la afluencia de emprendimientos foresto-industriales se especializó en la producción de maderas blandas para la producción de papel y de triturado (Borodowski y Suarez, 2004). Algunos de estos emprendimientos como Alto Paraná ${ }^{17}$, FAPLAC y Papel Prensa ${ }^{18}$, lograron prosperar y consolidarse en la región durante este período. Según un funcionario de la DPF y asesor técnico durante la ejecución del RPPF, esta incipiente base empresaria luego se amplía con los forestadores beneficiarios del régimen de promoción que comenzaron a establecer aserraderos, incorporando otros destinos a la producción de madera (Entrevista n. ${ }^{\circ} 4,2016$ ). La superficie de plantaciones se incrementa significativamente durante esta fase de promoción que llega hasta fines de los años 90, definiendo el perfil forestal de esta región.

Según el Inventario Forestal (2009) en la ZNF 24328 ha estarían destinadas a usos forestales. A través del análisis de una base de datos proporcionada por la DPF, el $72 \%$ de esa área fue afectada por la Ley 25080 recibiendo sus titulares los ANR para plantación y otras labores forestales (poda, raleo y manejo del rebrote). También fue posible calcular la superficie subsidiada por cada titular en el período de tiempo 2002-2009.

${ }^{19}$ De los 91 titulares que componen la base de datos, el 60\% de los forestadores corresponde a la categoría "pequeños" ${ }^{20}$ que obtuvieron el financiamiento para el 8,7\% de la superficie total subsidiada que asciende a 1500 ha. Dentro del grupo de los denominados "grandes forestadores", se destaca un segmento de 6 empresas que, con una escala promedio de 1700 ha subsidiadas por titular, concentra el $64 \%$ de la superficie forestal 
que asciende a más de 10000 ha. Este segmento está compuesto por Papel Prensa, Alto Paraná y otras cuatro empresas. Cabe destacar la envergadura de estos emprendimientos integrados con la foresto-industria, con un elevado nivel tecnológico y de infraestructura, que aún con producción propia, se constituyen en los principales demandantes de madera, estructurando el mercado de productos y de trabajo a nivel local (Entrevista n..$^{\circ}$ 1, 2014: Asesor de medianas y grandes empresas. Accionista y consultor).

Si bien los ANR de esta última Ley no condicionan la permanencia en la actividad forestal de cada una de estas empresas, como sí es en el caso de los pequeños productores ${ }^{21}$, el interés en mantener un estrecho vínculo con el Estado se torna evidente en la perspectiva histórica. La evaluación que realizan referentes de AFoA, organización de la cual forman parte Papel Prensa y Alto Paraná, es que la Ley 25080 "no ha sido del todo exitosa", considerando que no ha alcanzado las metas propuestas en cuanto a la superficie forestal incrementada y el desarrollo de la cadena foresto-industrial. No obstante, aunque con ajustes, apuestan a la continuidad de la misma a través de las prórrogas y modificaciones en su implementación para hacer más efectivo el mecanismo de promoción forestal.

Estos elementos permiten iluminar una dimensión del impacto de las políticas de intervención que profundiza la tradicional mirada acerca de los ganadores o perdedores, y que siguiendo a Long $(2007$, p. 78$)$ indaga en el modo en cómo se reestructuran las relaciones sociales a partir de la legitimación de los distintos agentes que promueven los instrumentos de políticas públicas. En el caso de las políticas forestales, más allá de la inclusión tardía del pequeño forestador como destinatario de instrumentos de fomento, es el productor empresarial que se constituye como sujeto central de estas políticas. Este cuenta con la capacidad de inversión, genera índices de impacto (volumen y/o superficie) y contribuye al escenario deseado por el referencial descripto en lo que respecta a reducir el déficit de la balanza de pagos, fomentar el crecimiento forestoindustrial y constituir un mercado exportador. Por otro lado, incorporan en su discurso una jerga ambiental e incluso participan en la elaboración de las buenas prácticas para una forestación sustentable que legitima su posición en el escenario actual (Pizarro y Straccia, 2016). Más aún, bajo una lógica de agronegocio y con representaciones corporativas, estos logran avanzar en sus intereses de acumulación de capital, apoyándose en una histórica relación con el Estado, reestructurando la configuración socioproductiva local como en el Delta Inferior del Paraná.

\section{REFLEXIONES FINALES}

A partir de la aproximación teórica metodológica escogida, hemos intentando dar cuenta de las continuidades y cambios en la política sectorial forestal en la Argentina mediante el análisis contextualizado de los elementos que constituyeron su referencial.

Los factores económicos que componen la problematización de la realidad nacional del mercado de madera y papel en el contexto internacional, así como el déficit de la balanza comercial y la potencialidad de generar economías agroindustriales generadoras de trabajo y saldos exportables, permanecen vigentes desde el período de Industrialización por Sustitución de Importaciones hasta la actualidad. Sin embargo el hipotético amplio potencial ecológico para el desarrollo forestal en el país, ha sufrido un ordenamiento en base a la institucionalización y normativas de carácter ambiental a partir de la década de los noventa, como por ejemplo por aquellas que regulan la protección de áreas de bosque nativo respecto al avance de la frontera agropecuaria. Respecto a los sujetos económicos que encarnarían la transformación social deseada por las políticas públicas en el sector forestal, observamos que las sucesivas instrumentaciones de promoción forestal e industrial se orientan a favorecer a aquellos segmentos de mayor poder económico, los empresarios y grandes forestadores. No obstante, en el contexto neoliberal en el cual la vulnerabilidad de los pequeños y medianos productores agrarios se torna en una cuestión de Estado insoslayable, la inclusión formal de los pequeños forestadores como destinatarios de la política sectorial se formaliza. De todas maneras, los instrumentos de fomento de experiencias asociativas entre pequeños productores para aumentar la escala forestal no 
alcanzaron resultados significativos. Más aún, su inclusión tardía como destinatarios tropieza en un escenario en el cual los intereses corporativos de los empresarios forestales e industriales ya han consolidado su espacio en la mesa de negociación con el Estado. Estas entidades corporativas de nueva generación, que combinan la lógica del agronegocio, un perfil experto, un discurso que incorpora elementos ambientalistas y una actitud dialoguista como es el caso de AFoA, se constituyen en referentes ineludibles para la elaboración, difusión e implementación de las políticas sectoriales.

Las tensiones precedentes repercuten en la incidencia de la política sectorial forestal en los territorios destinatarios donde se reestructuran las relaciones sociales a partir de la legitimación de estos agentes específicos que promueven los instrumentos de políticas públicas. En el caso analizado del Delta Inferior del Paraná, se observa que las políticas estatales contribuyeron a asegurar el proceso de forestalización iniciado en los años 70 que registra Galafassi (2004) mediante inversiones foresto-industriales como Papel Prensa SA y la promoción financiera y fiscal de productores empresarios. Si bien se registra una mayor apertura en la política sectorial actual hacia la inclusión de los pequeños forestadores, los empresarios mantienen una posición privilegiada en la captación de los instrumentos de promoción económica del Estado.

\section{LEYES, NORMAS Y DECRETOS (RECUPERADAS EN HTTP://WWW.INFOLEG.GOV.AR)}

Decreto-Ley 4905 (1958). Modificación de la Constitución del Consejo de Administración Nacional de Bosques

Decreto 2284 (1991). Desregulación Económica. Reforma fiscal.

Decreto 133 (1999). Reglamentación de la Ley $\mathrm{N}^{\circ} 25080$.

Ley $N^{\circ} 13273$ (1948). Ley de Defensa, Mejoramiento y Ampliación de Bosques.

Ley No 19312 (1969). Fondo para el Desarrollo de la Producción de Papel Prensa y de Celulosa - Creación

Ley $\mathrm{N}^{\circ} 20531$ (1973). Ley de Promoción Industrial. Industria Forestal.

Ley $\mathrm{N}^{\circ} 21695$ (1977). Ley de crédito fiscal para forestación.

Ley $\mathrm{N}^{\circ} 24857$ (1997). Ley de Estabilidad Fiscal para forestación.

Ley $\mathrm{N}^{\circ} 25080$ (1999). Ley de Inversiones para bosques cultivados.

Norma 29976 (1993). Forestación. Instrumentación de Régimen de Promoción de Plantaciones Forestales.

Resolución 778 (1992). Forestación. Promoción de Plantación Forestal

\section{REFERENCIAS}

Blacha, L. y Magallán, M. (2015). Actores del mundo rural: elites, chacareros y arrendatarios. Buenos Aires: Universidad Nacional de Quilmes.

Borodowski, E. y Suarez, R. (2004). Álamos y sauces en el Delta del Paraná: situación del sector y silvicultura. Actas II Jornadas de Salicáceas. Buenos Aires, Argentina.

Borrelli, M. (2008). "Una batalla ganada": el diario Clarín frente a la compra de Papel Prensa por parte de los diarios La Nación, Clarín y La Razón (1976-1978). Papeles de trabajo 2(4). Recuperado en http://www.idaes.edu.ar/p apelesdetrabajo/paginas/Documentos/04_Minidosier_10_MarceloBorrelli.pdf

Cáceres, D. (2015). Tecnología Agropecuaria y Agronegocios. La Lógica Subyacente del Modelo Tecnológico Dominante. Mundo Agrario 16(31), 1-30 Recuperado en http://www.mundoagrario.unlp.edu.ar/article/view /MAv16n31a08/6639

Cartilla Forestal (1951). Publicación Técnica 16. Ministerio de Agricultura y Ganadería. Argentina.

Cobelo, C. (2005). La intervención del estado y la organización comunitaria. Construyendo endicamientos en el Delta bonaerense del Río Paraná. En: Benencia R. y C. Flood (coord.), Trayectorias y contextos. Organizaciones rurales en la Argentina de los noventa. Buenos Aires: Ed. La Colmena. 
Ferrer, A. (2010). La economía argentina. Buenos Aires: Fondo de Cultura Económica. (1era Ed. 1963).

Galafassi, G. (2000). Explotaciones familiares, división del trabajo y producción en el delta del Paraná, Argentina. Estudios Interdisciplinarios de América Latina y el Caribe 11(1). Recuperado en http://eial.tau.ac.il/index.php /eial/article/view/998

Galafassi, G. (2002). Reestructuración productiva, organización del proceso de trabajo y manejo de tecnologías: Un estudio de caso en la producción frutícola y forestal. Mundo Agrario 4, 1-27. Recuperado en http://www.mun doagrario.unlp.edu.ar/article/view/v02n04a02/1523

Galafassi, G. (2004). Historia Económica Social del Delta del Paraná. Cuadernos de Trabajo 17, 1-66. Veracruz, México. Universidad Veracruzana

Getino, O. (1995). Las industrias culturales en la Argentina. Buenos Aires: Colihue.

Gras, C. y Hernández, V. (2013). El agro como negocio. Producción, sociedad y territorios en la globalización. Buenos Aires: Biblos.

Jobert, B. y Muller, P. (1987). L'Etat en Action. Politiques publiques et corporatismes. Paris: PUF.

Kandus, P. y Minotti, P. (2010). Distribución de terraplenes y áreas endicadas en la región del Delta del Paraná. En: Blanco, E. y Mendez, F. (Eds.), Endicamientos y terraplenes en el Delta del Paraná. Fund. para la Conservación y el Uso Sustentable de los Humedales. Recuperado en http://server.ege.fcen.uba.ar/pcourtalon/PDF4LIBRO _WETLAND2010.pdf

Lajer, A. y Tempestoso, M. (2010). El complejo celulósico-papelero argentino en la industria sustitutiva de importaciones. $2{ }^{\circ}$ Congreso Latinoamericano de Historia Económica, México.

Lattuada, M. (2014). Políticas de desarrollo rural en la Argentina. Conceptos, contexto y transformaciones. Temas y Debates, 27, 13-47. Recuperado en http://www.scielo.org.ar/scielo.php?script=sci_arttext\&pid=S1853-984X2 014000100001

Long, N. (2007). Sociología del Desarrollo. Una perspectiva centrada en el actor. México: El Colegio de San Luis.

Lucero Manzano, M. A., Tapella, E., Signorelli, A. y Battistella, A. (2014). Grupo De Consulta Mutua Río Carabelas. La Región Del Delta. Producción Forestal, 10, 20-22. Recuperado en https://www.agroindustria.gob.ar/sitio/a reas/ss_desarrollo_foresto_industrial/_archivos/revista-produccion-forestal/10.pdf

Manzanal, M., Arzeno, M. y Nardi, A. (2011). Desarrollo, territorio y desigualdad en la globalización. Conflictos actuales en la agricultura familiar del nordeste de Misiones, Argentina. Mundo Agrario, 12(23), 1-38. Recuperado en http://www.mundoagrario.unlp.edu.ar/article/view/v12n23a04/174

Ministerio de Agricultura, Ganadería y Pesca de la Nación (2016). Estadísticas de la Subs. de Desarrollo de la Foresto Industria. Recuperado en http://forestoindustria.magyp.gob.ar/estadísticas

Ministerio de Ciencia, Tecnología e Innovación Productiva (2013). Argentina Innovadora 2020. Mesa "Producción y Procesamiento de Recursos Forestales". Recuperado en http://www.argentinainnovadora2020.mincyt.gob.ar/? wpfb_dl=64 (Error 8: El enlace externo www.argentinainnovadora2020.mincyt.gob.ar/?wpfb_dl=64 debe ser una url) (Error 9: La url www.argentinainnovadora2020.mincyt.gob.ar/?wpfb_dl=64 no esta bien escrita)

Muller, P. (2000). Las políticas públicas entre sectores y territorios. INNOVAR, revista de ciencias administrativas y sociales, 16, 55-64. Recuperado en http://www.bdigital.unal.edu.co/26724/1/24373-85373-1-PB.pdf

Muller, P. (2002). Las Politicas Públicas. Colombia: Universidad Externado de Colombia.

Olemberg, D. (2014). Formas Actuales de la Organización Social de la Producción Forestal en el Bajo Delta del Río Paraná (Tesis de doctorado). FCA-Un. Nac. de Córdoba. Recuperado en http://inta.gob.ar/sites/default/files/ script-tmp-inta_-_formas_actuales_de_la_organizacion_social_de_l.pdf

Oszlak, O. y O'donnell, G. (1981). Estado y políticas estatales en América Latina: hacia una estrategia de investigación. Buenos Aires, Centro de Estudios de Estado y Sociedad (CEDES), Documento G.E. CLACSO/N4, pág. 116-118.

Pizarro, C. (2014). Viejos y nuevos inmigrantes en la construcción del territorio denominado núcleo forestal del Delta Inferior del río Paraná, Argentina. Conferencia Conjunta Internacional FLACSO-ISA. Recuperado 
en http://web.isanet.org/Web/Conferences/FLACSO-ISA\%20BuenosAires\%202014/Archive/82ad8c05-de 61-4747-a8fb-73159c046ca9.pdf

Pizarro, C., Moreira, J. y Ciccale Smit, M. (2013). Vino la marea y nos dejó en la vía. Experiencias de las inundaciones de productores forestales en un área del Delta Inferior del río Paraná. II Encuentro Sudamericano de Estudios Agrarios. Recuperado en http://www.ina.gov.ar/ifrh-2016/trabajos/IFRH_2016_paper_18.pdf

Pizarro, C. y Straccia, P. (2016). "Isleños"y "ambientalistas". Confrontaciones sobre la sustentabilidad de la producción forestal en los humedales del Delta del Paraná (2012-2013)." En Roberto Benencia (edit.), Ruralidades, actividades económicas y mercados de trabajo en el Delta vecino a la Región Metropolitana de Buenos Aires. Buenos Aires: Fundación CICCUS.

Sánchez Acosta, M. y Vera, L. (2005). Situación foresto-industrial de Argentina al 2005 (Ejemplo de una cadena forestal). IPEF, Serie Técnica, 35, 23-44. Sivak, M. (2012). Clarín, un Invento Argentino. Canal Encuentro. Recuperado en http://www.tvpublica.com.ar/programa/clarin-un-invento-argentino-2/

Sivak, M. (2012). Clarín, un Invento Argentino. Canal Encuentro. Recuperado en http://www.tvpublica.com.ar/pr ograma/clarin-un-invento-argentino-2/

Surel, Y. (2008). Las Políticas Públicas como Paradigmas. Estudios Políticos, 33, 41-65.

Valtriani, A. (2008). Modelos de desarrollo forestal, sus conflictos y perspectivas en el sector de micro PyMES forestales. Estudios de caso en la región noroeste y centro de la provincia de Chubut (Tesis de doctorado). Universidad de Buenos Aires.

Zarrilli, A. (2008). Bosques y agricultura: una mirada a los límites históricos de sustentabilidad de los bosques argentinos en un contexto de la explotación capitalista en el siglo xx. Revista Luna Azul, 26, 87-106. Recuperado en http://www.scielo.org.co/pdf/luaz/n26/n26a05.pdf

\section{Notas}

1 PICT n. 2.456 (2011-2015) "Las relaciones de mediación social en los procesos de apropiación de los recursos naturales", dirigido por B. Nussbaumer; PIP 0247CO (2016-2019) “las cuestiones del desarrollo, de lo indígena y de lo ambiental en la reconfiguración de lo rural”, dirigido por C. Cowan Ros.

2 UBACyT 20920160100707BA (2014-2017) "Nosotros creamos el Delta". Discursos, prácticas y saberes sobre la relación sociedad/ naturaleza en la disputa por la definición del territorio de la zona núcleo forestal del Delta Inferior del río Paraná. Dirigido por C. Pizarro.

3 El concepto de estabilidad hace referencia a la carga tributaria total que soporta el contribuyente por concepto del pago de impuestos y tasas tanto a nivel nacional, provincial y municipal por un plazo de 30 a 50 años, salvo la carga fiscal generada por el Impuesto al Valor Agregado.

4 Debe destacarse el caso de Misiones, cuyas experiencias de pequeños agrupados representaron el 63\% del universo provincial de forestadores beneficiados, recibiendo el $11 \%$ del monto devengado y contribuyendo con el $11 \%$ de la superficie forestada provincial. Datos del período 2003-2016.MAGyP http://forestoindustria.magyp.gob.ar/index.ph $\mathrm{p}$ ? seccion $=$ estadisticas $\& b=$ promocion-de-plantacion.

5 Las cifras aquí elaboradas en el nivel nacional tienen como base los datos publicados por el MAGyP http://forestoindu stria.magyp.gob.ar/index.php?seccion=estadisticas $\& b=$ promocion-de-plantacion

6 Los pequeños forestadores son aquellos que reciben el apoyo financiero para máximo 10 ha de plantación forestal, hasta 50 ha de tareas (poda, raleo, manejo de rebrote), y pueden acceder a recibir un 50\% del ANR en forma adelantada. Los grandes forestadores son definidos por recibir la promoción financiera para más de 10 ha de forestación y más de 50 ha de tareas, teniendo en cuenta que los aportes quedan sujetos al criterio de escala de emprendimiento: si ocupa entre 1 y 300 ha, se subsidiará hasta el 80\% de los costos de implantación; si ocupa entre 301 y 500 ha, se subsidiará el 20\% de los costos de implantación.

7 Uno de los ejemplos más ilustrativos es la creación de la Corporación Forestal Neuquina (CORFONE) en el año 1974 como sociedad mixta con participación mayoritaria del Estado Provincial.

8 La Provincia de Buenos Aires fue la última en aprobar dicho ordenamiento en el año 2017, por lo que los pagos de los ANR quedaron cesantes desde el año 2013.

9 Una de ellas es la Asociación Forestal Mesopotámica creada en 2002. Su secretario afirmaba que un factor detonante de la creación de la Asociación fue haberse enterado que "en el 2001 algunas grandes empresas nucleadas en AFOA [reclamaban] ante el Ministro de Economía en turno, para que, ante la crisis, dejen de pagar los incentivos a las nuevas 
plantaciones forestales y les otorguen a los grandes los incentivos fiscales ya que podían reemplazar a los pequeños productores sin problemas, pues sostenían que tenían sistemas productivos altamente eficientes" (Escobar, P., 2015. Desde Afome calificaron de "fracaso" la política forestal para pequeños productores. http://misionesonline.net/2015/ 04/17/desde-afome-calificaron-de-fracaso-la-politica-forestal-para-pequenos-productores/.)

10 Entrevista $N^{\circ}$ 1, 2014: Asesor de medianas y grandes empresas. Accionista y consultor; Entrevista n. ${ }^{\circ} 2$, 2014: Asesor de empresas y representante de medianos y grandes productores.

11 Decreto Ley 701 del año 1974. Su aplicación fue extendida por diez años más a partir de la Ley Forestal de Chile sancionada en el año 1998.

12 En la página web de AFoA, a instancias del 71 aniversario de la Asociación, la editorial resumía su perfil institucional de la siguiente manera: "A lo largo de estos 71 años, AFoA ha sido partícipe de numerosos sucesos de magnitud para el sector como ser la Ley 13.273 de 1948 'Defensa de Nuestra Riqueza Forestal', la Ley 25.080 de 1999 de 'Inversiones para Bosques Cultivados', la prórroga de esta Ley en 2009 (26.432) y asistió como entidad de consulta en la Ley 26.331 en 2007 de 'Presupuestos Mínimos de Protección Ambiental de los Bosques Nativos'. Participó desde el inicio del Sistema Nacional de Certificación Forestal, es parte del Organismo Certificador de Trabajadores Forestales y de las Asociaciones vinculadas a la Certificación Forestal por gestión sostenible de bosques." http://afoa.org.ar/novedades_detalle.php?p= 174.

13 Dato del Inventario Forestal (1998), actualizado hasta 2009 por la DPF de la entonces SAGPyA.

14 Si bien solo el 11,60\% de la superficie total del Delta se encuentra protegida mediante endicamientos (Kandus y Minotti, 2010, p. 21), en el caso de la ZNF, esta cifra asciende al 60\%.

15 Para el análisis del impacto y los discursos ambientales en torno a la producción forestal, ver Pizarro y Straccia (2016).

16 De acuerdo con Lucero Manzano et al. (2014), en los años 80, personal de Papel Prensa fomentó la generación del Grupo Carabelas en el Delta para la asistencia mutua y el mejoramiento de la producción forestal en función garantizar la materia prima para abastecer su industria. En la actualidad muchos de ellos se han transformado en grandes productores con empresas dedicadas no sólo a la producción sino también al aserrado. Para mayores referencias sobre esta experiencia el n. 10 de la Revista Producción Forestal realiza una sistematización de casos de extensión en el país.

17 Alto Paraná S.A., es una empresa de la multinacional Arauco (capitales chilenos) que se instala en la Argentina en 1975. Tiene predios en Buenos Aires, Entre Ríos, Santa Fe y Misiones, provincia donde tiene una superficie total plantada de 233.000 ha, mientras que en el resto tiene 29.750 ha. De esta última cifra, el $15 \%$ se encuentra en continente y el $85 \%$ restante en las islas del delta bonaerense y entrerriano, produciendo anualmente 80.000 toneladas de materia prima que abastece parcialmente a la planta industrial de la misma empresa (http://www.altoparana.com.ar). En Buenos Aires (ZNF), el predio “Oasis" cuenta con 10.481 ha totales y 7.841 ha productivas. En Las Palmas, predio ubicado en Zárate, se encuentra la planta de aglomerados FAPLAC que fue adquirida en 2010 por Alto Paraná.

18 Papel Prensa posee 8.000 ha propias de las cuales 2.000 se encuentran en la ZNF. En el año 2015, consumía 360.000 toneladas anuales de madera (http://www.papelprensa.com) y es junto con Alto Paraná el mayor demandante de materia prima forestal en el Delta del Paraná (Entrevista n. ${ }^{\circ}$ 1, 2014: Asesor de medianas y grandes empresas. Accionista y consultor).

19 Para el análisis sobre la distribución de beneficios de la Ley 25080 se obtuvo una capa en formato "shape" con la superficie reconocida dentro del Inventario Forestal. Dicha capa contiene tanto la superficie que recibe los ANR como aquella que no. Se procedió a identificar exclusivamente a aquellos polígonos que se encontraban dentro de la ZNF. Se calculó su superficie total, la superficie inventariada como forestal y la que se corresponde con lotes (estrictamente polígonos forestales) que reciben beneficios por la ley 25.080. Un mismo lote no puede volver a recibir el subsidio dentro de un período menor al turno de corta estimado para la región y la especie.

20 Manteniendo las categorías establecidas por la Ley 25.080, el análisis de esta base de datos consideró como pequeño forestador a aquel con una superficie subsidiada de hasta 60 ha, correspondiendo este valor a la suma de hasta 10 ha de plantación y hasta 50 ha de tareas. Esta opción se realiza dado que no es posible identificar a los mismos por estratos socioeconómicos como pequeños productores, dado que se consigna solamente la superficie forestal como dato, excluyendo otros que permitirían una mayor especificación del sujeto social de referencia.

21 De acuerdo a una entrevista realizada en 2017 a un técnico de INTA Delta, la cesantía de pago (entre 2013 y 2017) de los planes forestales para los ANR de la Ley 25080 hasta tanto se aprobara el Ordenamiento Territorial de la Provincia de Buenos Aires, repercutió en que una porción significativa de pequeños productores abandonara sus plantaciones forestales (Entrevista n. ${ }^{\circ}$, Asesor Técnico y Extensionista, INTA Delta). 